\title{
Countermeasures of Community Elderly Care Service from the Perspective of Combination of Medical Care and Elderly Care
}

\author{
Xiufeng Chen \\ The First Affiliated Hospital of Anhui University of Science and Technology (Huainan First People’s Hospital), Huainan, 232007,
} Anhui, China.

\begin{abstract}
How to cite this paper: Xiufeng Chen. (2022) Countermeasures of Community Elderly Care Service from the Perspective of Combination of Medical Care and Elderly Care. International Journal of Clinical and Experimental Medicine Research, 6(1), 52-59.

DOI: 10.26855/ijcemr.2022.01.010
\end{abstract}

Received: November 8, 2021

Accepted: November 30, 2021

Published: January 5, 2022

*Corresponding author: Xiufeng Chen, The First Affiliated Hospital of Anhui University of Science and Technology (Huainan First People's Hospital), Huainan, 232007, Anhui, China. Email: 1363618418@qq.com

\begin{abstract}
Aging of population is an important social problem that our country begins to face, because the number of the elderly in our country is increasing year by year at the present stage, so our country should actively explore a good pension service model to meet the basic service needs of the elderly. Increasing number of elderly people in the medical security system of our country present stage and extremely far-reaching impact on social and economic development, so we should keep in medical combination under the perspective of family old-age security functions into full play, improve the community health care, rehabilitation and nursing function, expand the scope of capital investment in the community endowment, improve the service personnel's professional ability and the quantity. Finally, we should explore a good service model for the whole life cycle of the elderly. In order to better serve the elderly, through analyzing the factors that affect the attitude of the elderly population to the community's "integrated medical care" elderly care service, we will continuously upgrade the community's integrated medical care service and make it the best choice for the elderly to provide for the elderly.
\end{abstract}

\section{Keywords}

Combination of Medical Care and Nursing, Community Pension, Service Countermeasures

As a result of the gradual improvement of the living standard of our residents and the influence of the medical level of our country, the life of the elderly in our country has been significantly prolonged. At the same time, due to the gradual improvement of China's economic development level, China's fertility rate declined. All of these factors have led to the rapid growth of the elderly population in China, as well as the social phenomenon of aging, empty-netting and diversified family types. In the face of these social phenomena, China's socialized pension service supply at the present stage is difficult to meet the actual demand, so we need to develop community pension service.

\section{Current situation and problems of the combination of medical care and elderly care services}

\subsection{Lack of concept of combining medical care with old-age care}

First of all, the concept of combining medical care with nursing care is not fully defined in the actual work of elderly care services, which leads to the waste of resources or problems in the direction of resources input in the ac- 
tual implementation of elderly care services [1]. For the combination of old-age care services and medical services for the elderly, is it the common development of old-age care services and medical services for the elderly or the development of one leading the development of the other? At the same time, can the cost input of constructing medical service sector in nursing homes and the economic source of nursing homes fully meet the actual requirements of medical service provision? Whether the medical service providers with the nature of public welfare or medical insurance can meet the actual needs of community pension under the concept of combining medical care with nursing care? If not, how much capital investment and professional service personnel are needed? All these problems are important to be solved in the mode of combining medical care with old-age care. These questions have different answers in different regions of China. Therefore, clear guiding concepts should be established in policies and planning at the present stage to provide a theoretical basis for the establishment of follow-up old-age service models.

\subsection{Insufficient professional capacity and quantity of service personnel}

Secondly, the professional ability and quantity of service personnel are insufficient, which cannot fully meet the requirements of the coming aging society in China [2]. Under normal circumstances, with the increase of age, the elderly will lead to the decline of internal immunity, calcium loss, osteoporosis and other phenomena, in the face of different characteristics of the elderly should implement different pension measures, so the professional ability of China's pension service personnel at the present stage is required. At the same time, with the increasing number of the elderly in China, the number of pension service personnel is required. With the rapid development of aging in China, the demand for professional ability and quantity of service personnel is getting higher and higher. Therefore, attention should be paid to the training of service personnel to meet the needs of the elderly service.

\subsection{There is an imbalance in the combination of medical and nursing resources}

Finally, there is the imbalance of resources in the combination of medical and nursing care. At present, pension service resources are generally concentrated in the city, even the community pension model is basically implemented in the city as a unit, which leads to excessive concentration of medical resources in the city. In contrast, there are a large number of rural elderlies in China at the present stage. Firstly, most of the rural elderly are empty-nesters, so they cannot fully enjoy good family maintenance measures. Secondly, the living places of the elderly in rural areas are scattered, and the need for medical resources is relatively large. However, the basic medical service resources in rural areas of China are extremely limited, which cannot meet the huge demand for old-age services. Therefore, in the combination of medical care and elderly care, there are problems of unbalanced distribution of endowment service resources and imbalance of supply and demand [3].

\subsection{The relevant system and laws and regulations are not perfect, and it is difficult to achieve a good merger of the system}

In order to build a good community pension service system, the most important work is to embed medical and health work into the pension service work, so that the health examination, disease treatment, rehabilitation care and hospice comfort in medical and health can be well permeated into the work of China's community pension center. However, under the current social background, pension service and medical service are two completely different systems. Among them, pension service belongs to the jurisdiction of civil affairs department, while medical service belongs to the jurisdiction of health department. At present, China does not have a good system or laws and regulations to infiltrate medical and health services into the actual pension work, and there is no relevant system and laws and regulations to combine medical and health services with pension services. As a result, medical and health services lack certain control means in the actual implementation of elderly care work, and it also leads to many medical and health services cannot be implemented in the actual community elderly care work. As a result, in the process of implementing the community pension model, it cannot provide adequate medical and health care services, and unhealthy social activities such as illegal fund-raising may also occur.

\section{Measures to combine medical care with community elderly care services}

\subsection{Expand the way of capital investment in community pension}

In order to meet the needs of limited community endowment resources and insufficient cost investment in China at the present stage, the model of capital investment in community endowment should be expanded, which can not 
only help the community medical-care combination endowment resources to be fully utilized, but also help enterprises to obtain good social benefits and achieve win-win goals [4]. First of all, the state and government can formulate fiscal and tax policies related to the resources invested by enterprises in the community pension mode, which can provide policy assistance or fiscal and tax reduction measures to help enterprises reduce the input cost, which can also stimulate the enthusiasm of enterprises. Secondly, the state and the government can formulate certain financial subsidies, through the implementation of this way to fully improve the enthusiasm of enterprises to invest resources in community pension. Like money number of different countries to enterprises, to develop year-on-year fiscal funds to carry out the system, so plus countries offer tax breaks, can help enterprises to gain economic benefits, to some extent at the same time, enterprises in the process of implementing can give full play to its own advertising advantage to help enterprises to obtain good social benefits. This can significantly improve the enthusiasm of enterprises to invest funds and resources in community pension, and then promote the improvement of community pension service level. At the same time, China should fully explore the centralized system of pension funds within the community. For example, the state can improve the pension collection amount of the elderly before retirement to a certain extent, and alleviate the current situation of insufficient pension funds in the community through the implementation of this method. In addition, the country should fully innovate the pension insurance and pension fund use system, so as to expand the depth of some capital investment in community pension through this way. The country can alleviate the social pension problems caused by aging in China by reducing the price of medicines commonly used in pension services. Through the full implementation of the above systems, the final guarantee of all-round, full life cycle service quality of the elderly.

Finally, the state or government should give full play to the power of public welfare organizations in the society to improve the attention of public welfare organizations to support the elderly care services in the aging society, and then implement relevant measures. Local governments can organize NGO managers to visit institutions and facilities related to community pension, helping NGOs to understand the model of community pension and the role of community pension on society. In this context, even if public welfare organizations cannot provide certain financial support, they can also enlist their members to provide certain assistance to community elderly care services. For example, public welfare organizations can cooperate with relevant enterprises and internal members to carry out volunteer activities or donation activities. Through the effective implementation of this method, community elderly care services can quickly improve the quality. At the same time, other organizations in the society can also give full play to the public welfare to help community elderly care, for example, schools can organize students to do volunteer work in the community. According to the actual investigation, the appearance of children can obviously relieve the pressure of the elderly, so as to lay a good spiritual foundation for the elderly to accept community care services.

\subsection{Strengthen the training of professional service personnel}

To strengthen the training of professional service personnel, we can start from improving the professional ability of service personnel and the number of service personnel [5]. The first is to improve the professional ability and professional quality of existing service personnel, to provide high-quality services for the elderly at this stage. Community elderly care service providers can cooperate with medical colleges and universities. Community elderly care service providers can provide certain internship positions for students in medical colleges and universities, while professional teachers in medical colleges and universities can provide specialized training for professionals in community elderly care service providers. Through the implementation of this way to fully improve the professional ability and professional quality of service personnel, and then improve the quality of elderly care services. For example, professional teachers in medical colleges and universities can give special nursing lectures on osteoporosis, hypertension and other diseases common to the elderly, so as to help service personnel improve their basic awareness and professional ability. Or the community pension department should invite doctors in hospitals to provide guidance and training at work, so as to fully improve the professional ability and service ability of service personnel. In the process of implementing guidance and training, doctors in hospitals should first explain common chronic disease care measures for the elderly, examination measures, emergency treatment measures and timely judgment of the elderly's physical fitness. After that, the existing pension service providers should combine their knowledge and the condition and physical health characteristics of the elderly they care for to ask questions, and the doctors put forward targeted solutions according to the questions asked by the service personnel. This can effectively improve the quality of elderly care services, and finally fully meet the needs of elderly care services. In addition, community pension service departments should implement certain assessment system and incentive system, 
and take the training content as the actual assessment content. Employees who pass the assessment system can get certain material rewards, so as to fully improve the enthusiasm of service employees to actively develop their professional ability and professional quality. This will significantly promote the provision of higher quality services by the community elderly service sector.

There is also to strengthen the number of professional service personnel training, China's medical colleges and universities should fully create community pension related majors according to the current situation of aging medical work demand, improve the enrollment, through this way to improve the number and quality of community pension service professionals. At the same time, the state should formulate favorable treatment implementation policies and work facilitation systems for community pension service departments, such as ensuring the benefits of five social insurances and one housing fund, to fully meet the needs of working hours. In this way, we can improve the popularity of community pension related majors, and finally fully increase the number of high school graduates who choose community pension related majors, so as to improve the overall number of community pension service staff. The state can also give full play to the role of amateur workers. For example, for non-front-line workers who have worked in the medical sector for a long time, relevant departments can organize professional and technical personnel to train these workers. First of all, these workers know certain medical and maintenance knowledge, so they need a period of training to adapt to the work requirements of community pension. Secondly, the training time of these workers is obviously shorter than the training practice of professional and technical personnel, so they can give priority to meeting the actual requirements of community pension service and improve the number of basic pension service providers. It is necessary to pay attention to the good identification and selection of these workers, to avoid damage to the health of the elderly on the basis of the actual provision of old-age care services.

\subsection{Realize the integration of medical and elderly care service resource elements}

The integration of community elderly care service resources combined with medical care can help high-quality medical service resources give full play to their advantages and alleviate the imbalance between supply and demand of elderly care resources in China at the present stage [6]. In the implementation of this step, we should fully clarify the contents and elements covered in old-age care services, such as service objects, service subjects, service contents, implementation methods and required qualifications and standards. Both "medical care" and "old-age care" need accurate positioning. It is not possible to simply increase service institutions without controlling the actual service quality. In this way, the quality of community pension service may not be up to the standard, which ultimately leads to the community pension model cannot fully play the role of meeting the needs of China's aging society, and it is easy to breed corruption. Therefore, relevant departments should formulate good management measures for the operation status of community pension service delivery organizations at the present stage, carry out practical management for the problems in the operation process, and implement them into the system to achieve efficient management of relevant departments and organizations. In the implementation of community pension model, we should take the community as the actual platform, strengthen the construction of community service facilities, and give full play to the role of the community. At the same time, barrier-free transformation will be implemented within the community, convenient home-based elderly care services will be developed, and the combination of medical and health services and elderly care services will be actively promoted, so as to realize the integration and optimization of elderly care service system resources, give full play to the utility of resources, and improve service quality and efficiency. The community administration should first conduct a census of the number of elderly people in the community and the number of people who will retire within ten years, and then use the final data to build the relevant infrastructure. For example, necessary barrier-free access and barrier-free elevators can be built at the gate of residential buildings, which can effectively improve the quality of community elderly care services and improve residents' satisfaction. On this basis, the medical department can carry out regular check-up and consultation for the elderly in the community, and the individual responsibility system can be realized. In this way, the quality of the elderly service can be improved and the actual demand for the elderly can be finally met. The health management service mode of combining medical and nursing care is a mode of integrating endowment service resources.

In this model, priority is given to the elderly with disabilities, chronic diseases, relapses and terminal diseases, and different old-age services are provided for this elderly. At the same time, the basic services include life nursing, medical diagnosis and treatment, rehabilitation of serious diseases, hospice care and spiritual consolation. Under this service management model, public administration departments, for-profit organizations and non-profit public welfare organizations can work together to make contributions to providing good old-age services. At the same time, under the mode of combining medical and nursing care with health management service, hospitals, service institu- 
tions combining medical and nursing care and close planning service providers should be established in the community. The types of service personnel should also be more detailed and increased in the aging social background, because it takes too long to train professional doctors, so the types of nursing personnel can be increased, such as disabled elderly nursing personnel, chronic elderly nursing personnel and so on. Because the physical condition of many elderly people requires the cooperation of professional doctors and nursing staff, in this case, refining the types of professional nursing staff can effectively reduce the social demand for professional doctors. Therefore, it is required that China's vocational management departments should timely formulate a certain perspective of career planning and assessment system, through the implementation of this system to ensure that professional nursing staff on duty in time, so as to provide professional nursing services for different types of elderly people. Finally, it is necessary to strictly control the implementation of the qualifications and standards of departments providing elderly care services. On the one hand cannot meet the needs of pension service qualification as well as standard organization may appear endowment service does not reach the designated position, appear pocketing or is a threat to health of the elderly life phenomenon, on the other hand cannot meet the needs of pension service organization may be all in the name of providing services, appear the phenomenon of illegal fund-raising. Therefore, relevant national departments should formulate certain systems and policies to review and assess the qualifications and standards of organizations providing elderly care services, so as to ensure that they can provide healthy and complete community elderly care services and contribute to the physical health level of the elderly in China.

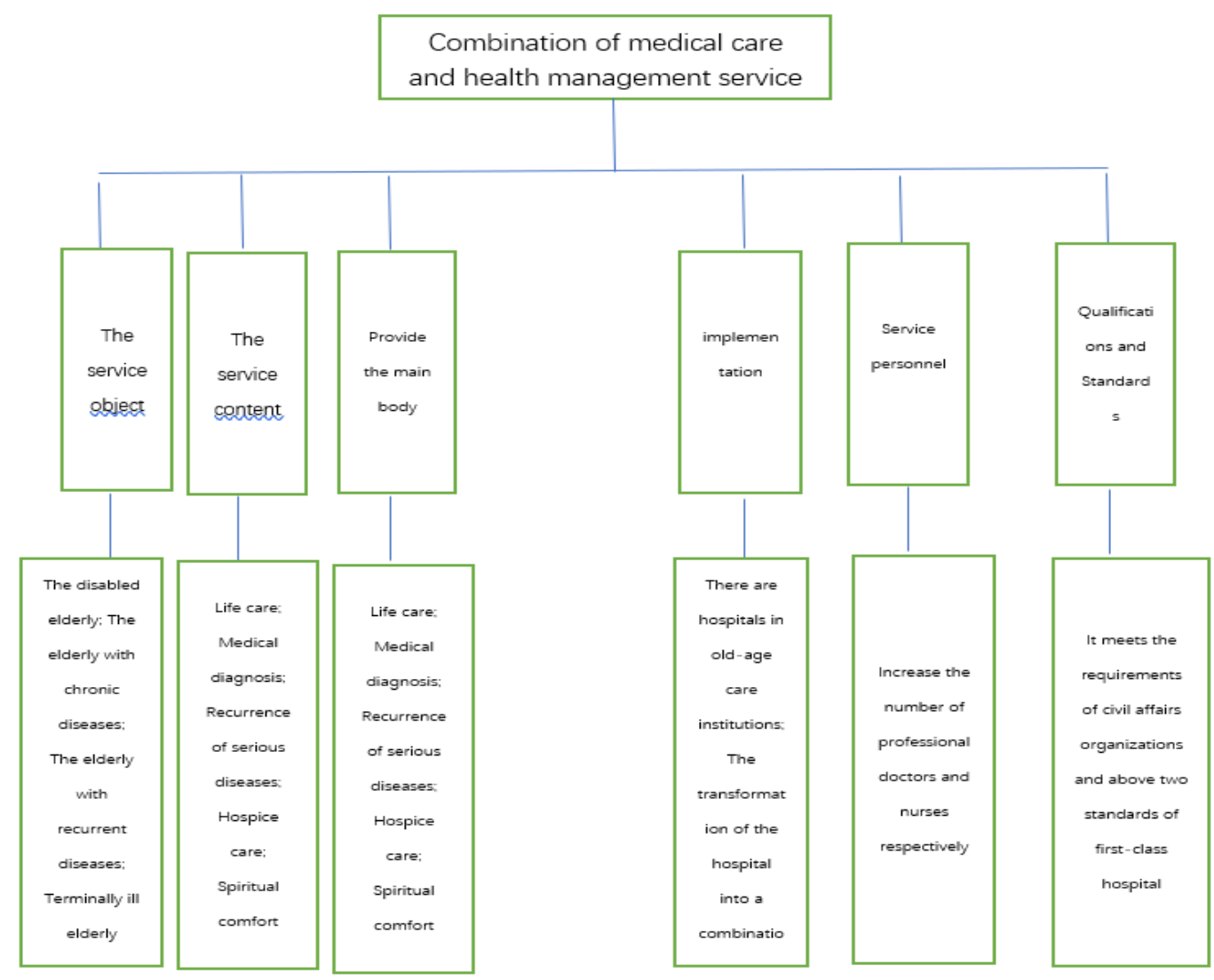

Figure 1. Medical and nursing integrated health management mode.

\subsection{Make full use of the advantages of information technology to build a service network}

In the process of establishing a new model of community pension service, the advantages of network technology can be fully brought into play. At present, the development of information technology and network technology in China can meet the requirements of establishing community elderly service network, so we should use modern information technology to build service network and improve service quality and efficiency. First, the service network is used to integrate medical service resources and community endowment resources, and then the number, age, medical records and other information of the elderly in the community are concentrated in the service network. At 
the same time, the nursing information, rehabilitation and medical information of the elderly in the community should be concentrated in the old-age service information platform. In this way, professional service personnel can combine the information in the information system to provide high-quality and targeted service measures for the elderly, whether it is service personnel to take care of the elderly at home or provide elderly care services in the elderly service department. For example, before the service, the elderly service professionals can find out that the elderly have osteoporosis, hypertension and other diseases according to their names in the system, and the elderly service providers can provide them with good massage services and dietary precautions. Through the advantage of information technology and network technology, fully improve the quality and efficiency of providing elderly care services. At the same time, in the establishment of the service network, we should establish a leading group system of old-age services, with the elderly as the center, to provide different old-age services.

In constructing a good pension after service system of leadership, can build the wisdom together health community network service platform, namely the elderly as the actual service center, the center established on the basis of elderly welfare homes, streets, street hospital, streets, elderly service centers, community endowment service center, as well as the community health service center. The main task of street welfare homes is to provide rehabilitation nursing services for the elderly, geriatric hospitals and community health service centers are to provide good medical services for the elderly. Among them, geriatric hospitals provide medical services mainly for the elderly, and community health service centers mainly for community residents. In the context of aging society, the elderly service window and beds are provided in the medical service institutions within the community. Street elderly service centers and community elderly service centers provide normal elderly care services. Community nursing service centers also need to provide socialized rehabilitation and nursing services for the disabled and mentally disabled elderly in the community, while Street Laffey hospital and elderly service center provide special care services for the childless and mentally disabled elderly. The establishment of these institutions and departments should be under the framework of the intelligent system of community medical and nursing Internet elderly services, and also under the command of the leading group of community office's medical and nursing integrated elderly services. In this way, it cannot only fully implement the humane treatment, but also achieve the goal of providing more efficient elderly services. Finally, it will provide efficient and high-quality health services for the elderly in our communities.

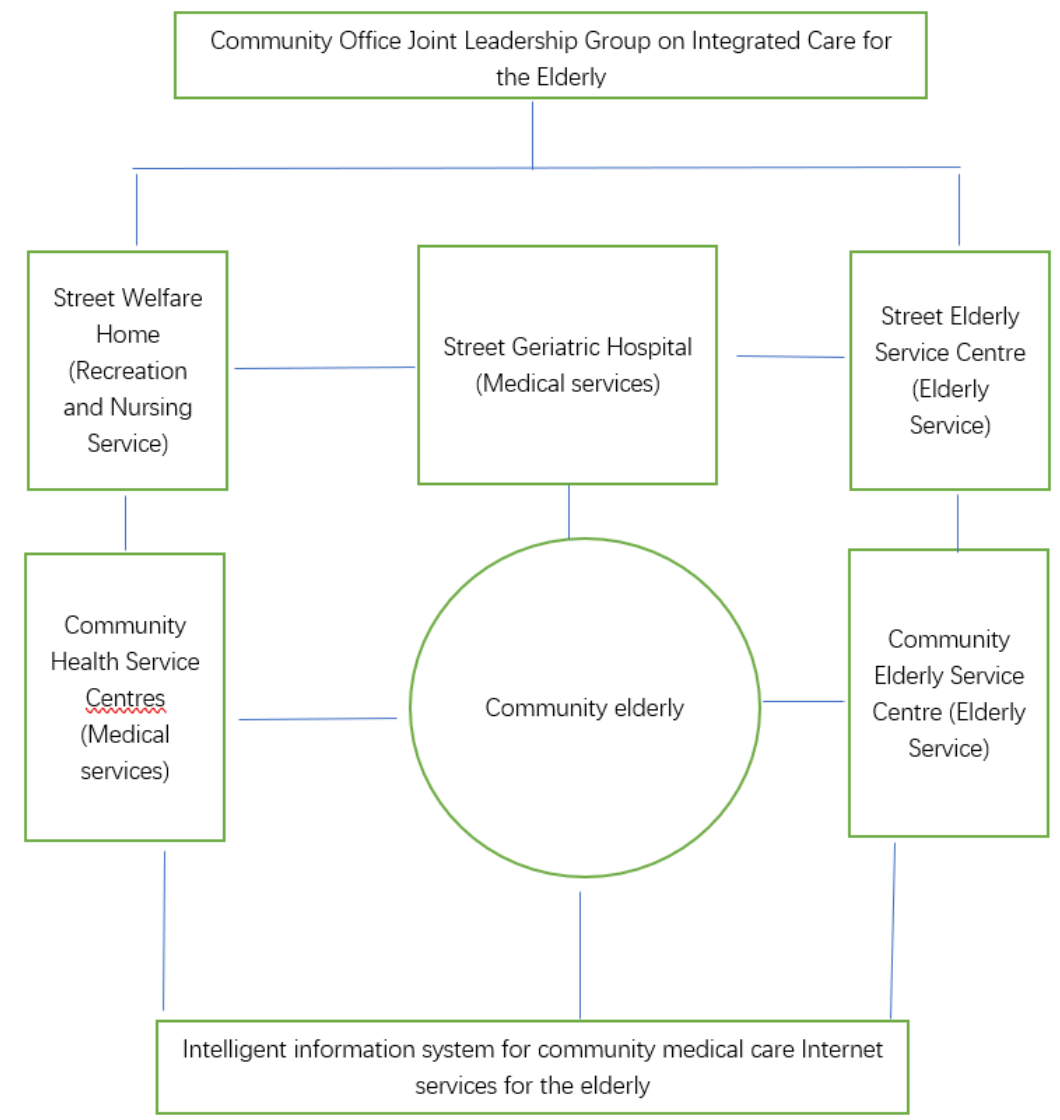

Figure 2. Smart health community network service platform. 


\subsection{Give full play to the role of family pension}

In China, the elderly has a large base and the number is increasing rapidly. In this social context, the elderly in China suffers from a large number of long-term diseases and chronic diseases, which cause a high mortality rate is chronic diseases. At present, nearly $70 \%$ of the elderly choose home community pension, indicating that most of the elderly do not like the atmosphere of nursing homes. In this context, the community pension service in China has posed a great challenge. For older people with chronic diseases, the risk is not only higher mortality, but also recurrent chronic diseases and the need for long-term treatment. Many elderly people need to go back and forth between family and hospital for a long time. Therefore, giving full play to the role of family pension can effectively relieve the pressure of community pension, and at the same time, giving full play to the role of family pension can relieve the psychological pressure of the elderly to a certain extent, thus laying a solid psychological foundation for the subsequent provision of community pension services. There are two main functions of family pension security. The first is to play the role of traditional family economic security. Under the influence of China's special historical characteristics, the economic support between family members plays a very important role in the elderly. The economic guarantee function played by the family is the material basis to guarantee the normal life of the elderly. The second is to play the role of family members in caring for the elderly. Under the influence of China's special history and culture, the more children, partners and grandchildren take care of the elderly, the more the elderly will reap a good sense of happiness. For the sick elderly, family care is more important in the elderly's mental health. According to the actual survey, among the elderly receiving community pension services, the elderly accompanied by their relatives have significantly better treatment effect. Whether old people fall ill or recover after illness, they cannot leave the company and spiritual support of their relatives. Therefore, giving full play to the role of family pension can effectively ensure the mental health level of the elderly, and then lay a good foundation for the follow-up community pension services and medical services. Therefore, family members should design more time to spend with the elderly in their actual life, or make a good plan to go home. Through the implementation of this method, it can play a good spiritual comfort and emotional support function.

\section{Conclusion}

In a word, in the context of China's aging society, we should give full play to the role of social forces and provide good pension services for the elderly, so as to complete the good care of the elderly in the whole life cycle. The state should establish a good model of community pension service, use information advantages, expand the space and scope of capital investment, through the implementation of these means to fully improve the quality of community pension service, to meet the health requirements of the elderly in China's aging society.

\section{Funding}

Key R\&D project sponsored by Anhui province (No.1804h08020289); Huainan City “50 • Science and Technology Star” Innovation Team.

\section{References}

[1] Wang Lanoxin, Huang Iulian. (2020). Countermeasures of community elderly care service from the perspective of medical care integration [J]. Academic Exchange, 2020, No.320(11): 145-154+194.

[2] Yang Li, Ouyang LINQ, LI Yanfeng, et al. (2019). Research on demand and countermeasures of institutional elderly care services in Changed city from the perspective of combination of medical care and nursing care [J]. Health Literature review, 2019, (11): 271-272.

[3] Huang Lankan, Mo Shenlong. (2021). Research on urban community home care service under the combination of medical care model—A case study of Shaping, Chongqing [J]. 2021(2017-10): 113-115.

[4] Qipao, M., Tian, H. G. (2019). Countermeasures and suggestions for the development of community "combination of medical care and elderly care” service [J]. Modern Commerce \& Trade Industry, 2019, 40(35): 2-2.

[5] Chen Lijun. (2019). Modern Marketing: Wealth Information Edition, 2019(2): 194-194.

[6] Yang Guotie, You Haumea, Hu Chenggang. (2021). Rethinking of community medical care combined with elderly care service planning in the context of epidemic prevention and control [J]. 2021(2020-7): 21-27.

[7] Yue Zhuoyi. (2020). Analysis on the current situation of home-based elderly care service in community integrating medical care and nursing $[\mathrm{J}]$. Cooperative Economy and Technology, 2020, (18): 178-179. 
[8] Xu Xiaowen, Zhang Xinkuan. (2013). Analysis of home-based elderly care services in urban communities in China [J]. Journal of Shandong Institute of Finance, 2013, (1).

[9] Ma Haiyan. (2014). Problems and Countermeasures of home-based elderly care service in urban communities [J]. Journal of Beijing Vocational College of Political Science and Law, 2014, (1): 111-114.

[10] Qiao Wen. (2019). Research on the mode of combining medical care with elderly care under the background of healthy aging in China [J]. Shenzhou, 2019, (12), 244-24. 